\title{
EARLY INITIATION OF BREAST FEEDING AMONG CHILDREN 0-23 MONTHS OF AGE AND ASSOCIATED FACTORS IN DISTRICT CHARSADDA, PAKISTAN
}

\section{Ayesha Imtiaz', Zia UI-Haq, ${ }^{1,2}$, Naveed Sadiq', Sheraz Fazid'}

\begin{abstract}
OBJECTIVE: To determine the practice of Early Initiation Breast Feeding(EIBF) and associated factors among mothers of children 0-23 months of age in district Charsadda, Khyber Pakhtunkhwa, Pakistan.

METHODS: This study was part of Khyber Pakhtunkhwa Integrated Population Health Survey (KPIPHS), 2016-17 and included data of 36 union councils from district Charsadda. Women having children $>2$ years of age $(n=357)$ were selected through multistage stratified-cluster random sampling. Data was collected using validated structured questionnaire. Association of breastfeeding practices was analyzed against a set of demographic variables through multivariable logistic regression analysis, using STATA- 15
\end{abstract}

RESULTS: Out of 357, 211 ( $59.10 \%$ ) children were breastfed within first hour after birth. Mean age of the mothers was $35.1 \pm 9.35$ years. About $49.58 \%$ $(n=177)$ of mothers were aging $26-35$ years, $63 \%(n=225)$ were rural residents, and $50.42 \%(n=180)$ were uneducated. In EIBF children, mothers between 26 35 years $(n=115 ; 54.4 \%)$, uneducated $(n=93 ; 44 \%)$, and residents of rural areas $(n=148: 70 \%)$ had a significant association $(p=\leq 0.05)$. In multivariable adjusted model, mothers between $26-35$ years (OR: I.8; $95 \% \mathrm{Cl}$ : I.I-2.9; $\mathrm{p}=0.025)$ and those living in rural areas (OR: $2.1 ; 95 \% \mathrm{Cl}: 1.3-3.5 ; \mathrm{p}=0.002$ ) were more likely to initiate breastfeeding earlier as compared to those living in urban areas and above 35 years of age after adjusting for other covariates.

CONCLUSION: More than half of the children under two years at district Charsadda were breastfed within first hour after birth. Residence, maternal age group, and school education had a strong association with EIBF.

KEY WORDS: Child (MeSH); Breast Feeding (MeSH); Feeding Behavior (MeSH); Parturition (MeSH); Pakistan (MeSH); Khyber Pakhtunkhwa Integrated Population Health Survey (Non-MeSH); KPIPHS-2016-I7 (Non-MeSH).

THIS ARTICLE MAY BE CITED AS: Imtiaz A, UI-Haq Z, Sadiq N, Fazid S. Early initiation of breast feeding among children 0-23 months of age and associated factors in district Charsadda, Pakistan. Khyber Med Univ J 2020; I2(2):95-I0I. DOI: I0.35845/kmuj.2020.19768.

\section{INTRODUCTION}

$\mathrm{A}_{\mathrm{R}}$ ccording to the Convention on the Rights of the Child "Every infant and child has the right to good nutrition". Adequate nutrition, is critical for improved child survival and healthy growth and development.' Optimizing nutrition during first 1000 days of life (from conception to 24 months of age) ensures the best possible start in life, with long-term benefits. ${ }^{2}$ Optimum Infant and young child feeding (IYCF) as recommended by World Health Organization (WHO) and United Nations International Children's Emergency Fund (UNICEF) starts with the initiation of breast feeding within first hour of birth followed by exclusive breastfeeding for the first six months of life, and introduction of nutritionally adequate and safe complementary
I. Institute of Public Health \& Social Sciences, Khyber Medical University, Peshawar, Pakistan

2. Honorary Clinical Senior Lecturer, Institute of Health \& Well-being, University of Glasgow, UK.

Email『:drzia@kmu.edu.pk, drzia80@yahoo.com, zia.ulhaq@glasgow.ac.uk Contact \# : +92-333-9258763

$\begin{array}{ll}\text { Date Submitted: } & \text { October II, } 2019 \\ \text { Date Revised: } & \text { June 19,2020 } \\ \text { Date Accepted: } & \text { June 20,2020 }\end{array}$

foods after six months, while continuing breastfeeding up to two years and beyond. ${ }^{1,3}$ Breastfeeding has important short-term and long-term benefits for neonates. ${ }^{4}$ Optimal breastfeeding if practiced, could save lives of more than 820,000 children under five every year.'

WHO recommends the early initiation of breastfeeding as it has important health benefits for both mother and the child. Breast-milk is an important source of energy and nutrients for children up to two years of age.' The breast milk produced in the first few days after delivery, known as colostrum, is highly nutritious. It contains antibodies that provide natural immunity to the newborn ${ }^{5}$; protecting them from acquiring infections and reduces neonatal mortality.' Early suckling also stimulates the release of prolactin and oxytocin, which help in the production and ejection of milk. It also reduces the risk of postpartum hemorrhage by stimulating uterine contraction after childbirth.

Despite of the benefits of optimal feeding practices, inadequate IYCF practices are reported in Pakistan. According to Pakistan Demographic and Health Survey (PDHS) $2017-18$, only $20 \%$ of children born in the last 2 years were breastfed within I hour of birth. ${ }^{5}$ More importantly the rate of Early Initiation of Breast Feeding (EIBF) has decreased from $46 \%(2006-7)^{6}$ to $19.6 \%(2017-18) .^{5}$ Maternal age, maternal education level, economic status, area of residence were identified as some of the socio-demographic factors found to be associated with early initiation of breast feeding. ${ }^{7-9}$ 

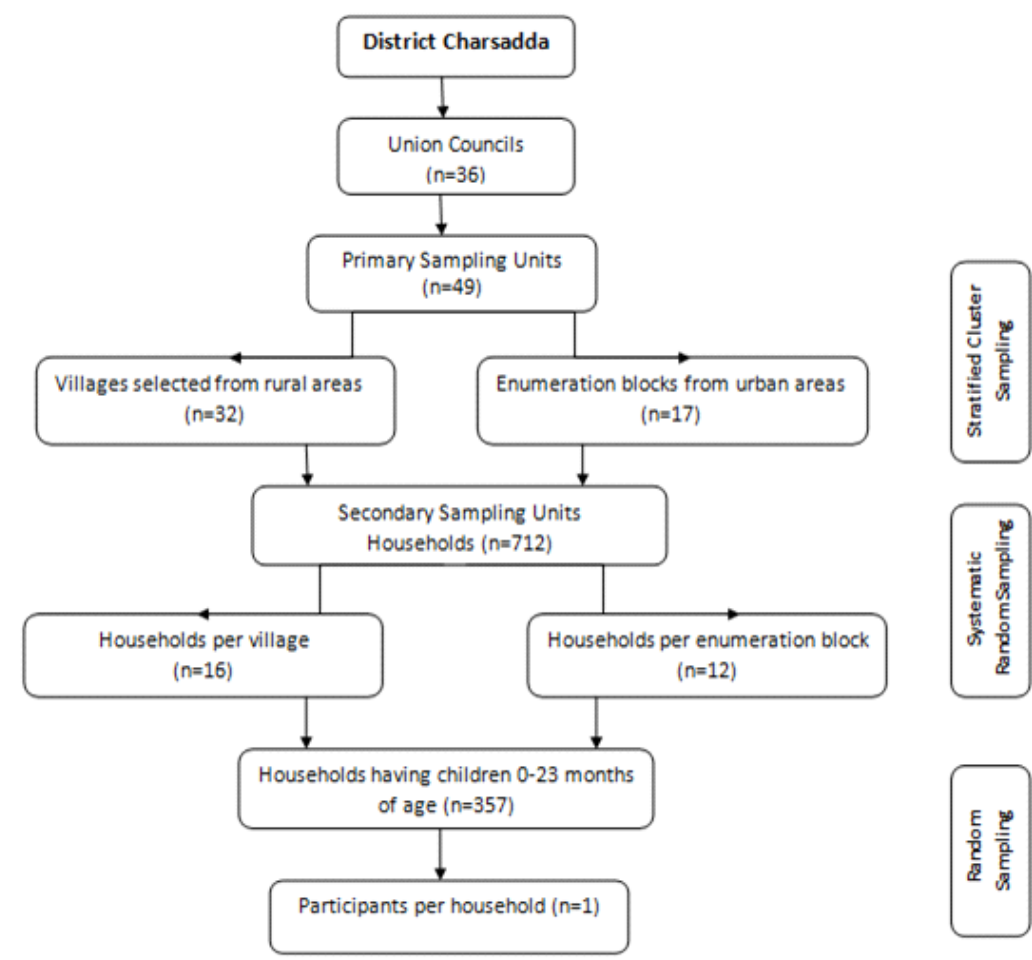

Figure I: Flow chart showing selection of participants through multi stratified cluster sampling

TABLE I: MATERNAL SOCIO-DEMOGRAPHIC CHARACTERISTICS IN DISTRICT CHARSADDA

\begin{tabular}{|l|l|c|c|}
\hline \multicolumn{2}{|c|}{ Characteristics } & $\begin{array}{c}\text { Frequency } \\
\text { N = 357 }\end{array}$ & $\begin{array}{c}\text { Percent } \\
(\%)\end{array}$ \\
\hline \multirow{3}{*}{ Residence } & Rural & 225 & 63.03 \\
\cline { 2 - 4 } & Urban & 132 & 36.97 \\
\hline \multirow{3}{*}{ Maternal Age Groups } & $\leq 25$ Years & 43 & 12.04 \\
\cline { 2 - 4 } & $26-35$ Years & 177 & 49.58 \\
\cline { 2 - 4 } & $>35$ Years & 137 & 38.38 \\
\hline \multirow{3}{*}{ School Education } & No school education & 180 & 50.42 \\
\cline { 2 - 4 } & $\leq 10$ years & 103 & 28.85 \\
\cline { 2 - 4 } & $>10$ years & 74 & 20.73 \\
\hline \multirow{2}{*}{ Monthly Household } & $\leq 10,000$ & 111 & 31.09 \\
\cline { 2 - 4 } & $11,000-20,000$ & 97 & 41.74 \\
\cline { 2 - 4 } & $>20,000$ & 61 & 27.17 \\
\hline \multirow{2}{*}{ Working status } & Housewife & & 17.09 \\
\cline { 2 - 4 } & Working women & 62.91 \\
\hline
\end{tabular}

Inadequate infant and child feeding practices contribute to the burden of infectious diseases and malnutrition. ${ }^{10}$ Optimal feeding is suggested to be one of the most effective strategies in improving child nutrition and reducing malnutrition; in turn contributing toward the better health of the population, poverty eradication, economic growth and sustainable development ${ }^{3}$. Population-based studies regarding EIBF practices in our setup are very limited. This study was conducted to determine the EIBF practices and associated sociodemographic factors in district
Charsadda of KP. This study was part of Khyber Pakhtunkhwa Integrated Population Health Survey (KP-IPHS), 2016-17; first population based crosssectional survey conducted in 24 districts of Khyber Pakhtunkhwa (KP), Pakistan." The findings of the study can be generalized to the population of district Charsadda. This study may provide evidence for developing rational policies and programs to impact the IYCF practices in KP.

\section{METHODS}

This study was part of Khyber Pakhtunkhwa Integrated Population Health Survey (KPIPHS), 2016-17," for which Ethical approval was taken from Ethical Review Board of Khyber Medical University, Peshawar, Pakistan. KP-IPHS was a first population based crosssectional survey conducted in 24 districts of KP, collecting information on socio-demographic and health indicators of population including children under five years of age, women of reproductive age group ( $15-49$ years) and adult males ( $>18$ years). The survey was conducted during 2016-17. Sampling for survey was done by Federal Bureau of Statistics, Pakistan." This study in district Charsadda, KP was conducted in all 36 union councils. Multi staged stratified cluster sampling was used for sample selection (Figure I). Total of 49 Primary Sampling Units (PSUs) were selected from all over district Charsadda which comprised of 32 villages from the rural areas and 17 enumeration blocks from the urban areas. Twelve households (Secondary Sampling Units - SSUs) were selected from each urban PSU and 16 households from each rural PSU, using systematic random sampling technique. A total 716 households were visited, among which 567 households agreed to participate in the study with response rate $79.2 \%$. Among these, 357 households had children of less than two years of age. Per house, one child was enrolled and if a household had more than one child of less than two years of age, then one child was selected randomly. Children delivered through cesarean section were excluded from the study.

The outcome measure for this study 
was the Early Initiation of Breast Feeding (EIBF) defined as "initiation of breastfeeding within the first hour of birth" as given in the survey questionnaire and measured as "proportion of children between 0-23 months of age, who are breast fed within first hour after birth". The explanatory variables included the mother's age in years, maternal education recorded as total years of school education, maternal occupation classified as housewives or working women having government or private job or business, monthly income of household (PKR), and area of residence (rural/urban). Data was collected through a set of standardized structured questionnaires developed by UNICEF and other working bodies after being customized to the necessities of local setup and needs. The questionnaire was designed in English and translated in local language. Mothers or the primary caretaker of the child were interviewed by data collectors, trained for the purpose."

Descriptive and inferential statistical analysis was performed using STATA version 15. Chi-square test was used to test the significance of association between EIBF and associated factors. Non-adjusted and multivariable logistic regression model was used to test the association of EIBF with other factors. $P$ value of $\leq 0.05$ at $95 \%$ confidence level was considered significant.

\section{RESULTS}

Out of 357,211 (59.10\%) children were breastfed within first hour after birth. Table I lists the sociodemographic characteristics of the surveyed participants. Total of 357 women had a mean age of $35.1 \pm 9.35$ years, average school education of $5.2 \pm 5.84$ years and median monthly income of 15000 PKR. Half of the women $(n=177)$ were in the age range of $26-35$ years and $50.4 \%$ had no school education $(n=180)$. Almost $63 \%$ $(n=225)$ of participants were rural resident, and $83 \%(n=296)$ were housewives, and $41.7 \%(n=149)$ had a monthly household income between II,000-20,000 PKR.

Table: Il shows the bi-variate association of Early Initiation of Breast Feeding (EIBF) with maternal sociodemographic characteristics. The area of residence, maternal age, and maternal education level were found to be significantly associated with EIBF. Among those who were breast fed, two third (70\%) were found to be living in rural areas, $54.5 \%$ were in the agerange of 26 to 35 years, and $44 \%$ had no

TABLE II: MATERNAL SOCIO-DEMOGRAPHIC CHARACTERISTICS ASSOCIATED WITH EARLY INITIATION OF BREAST FEEDING AMONG CHILDREN 0-23 MONTHS OF AGE IN DISTRICT CHARSADDA

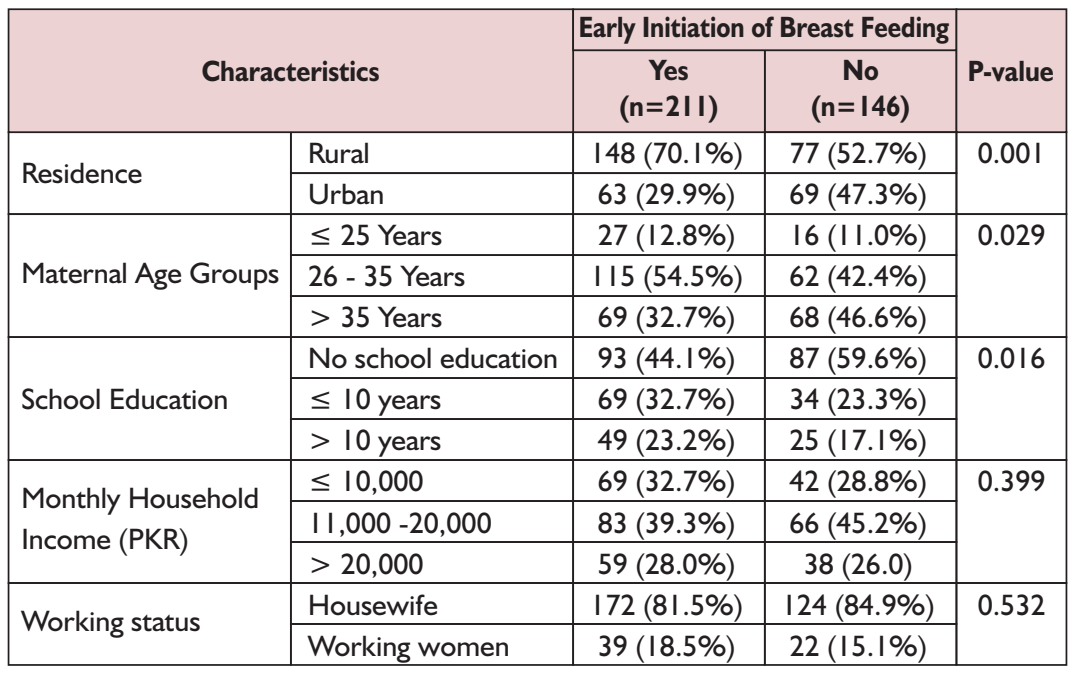

TABLE III: LOGISTIC REGRESSION ANALYSIS OF MATERNAL SOCIODEMOGRAPHIC CHARACTERISTICS ASSOCIATED WITH EARLY INITIATION OF BREAST FEEDING AMONG CHILDREN 0 - 23 MONTHS OF AGE

\begin{tabular}{|c|c|c|c|c|c|}
\hline \multirow{2}{*}{\multicolumn{2}{|c|}{ Characteristics }} & \multicolumn{2}{|c|}{ Univariate } & \multicolumn{2}{|c|}{ Multivariate } \\
\hline & & \multirow[t]{2}{*}{$\begin{array}{c}\text { Unadjusted OR } \\
95 \% \mathrm{Cl} \\
\end{array}$} & \multirow{2}{*}{$\frac{P \text {-value }}{\operatorname{Re}}$} & \multirow{2}{*}{$\begin{array}{c}\text { Adjusted OR } \\
95 \% \mathrm{Cl} \\
\end{array}$} & \multirow[t]{2}{*}{ P-value } \\
\hline \multirow{2}{*}{ Residence } & Urban & & & & \\
\hline & Rural & $2.1 \mathrm{I}(1.37-3.26)$ & $<0.001$ & $2.14(1.32-3.46)$ & $0.002^{*}$ \\
\hline \multirow{3}{*}{$\begin{array}{l}\text { Maternal Age } \\
\text { Groups }\end{array}$} & $>35$ Years & \multicolumn{4}{|c|}{ Ref } \\
\hline & 26 - 35 Years & $1.83(1.16-2.88)$ & 0.009 & I.78(I.08-2.95) & $0.025^{*}$ \\
\hline & $\leq 25$ Years & $1.66(0.82-3.36)$ & 0.156 & $1.33(0.62-2.87)$ & 0.464 \\
\hline \multirow{3}{*}{$\begin{array}{l}\text { School } \\
\text { Education }\end{array}$} & No school education & \multicolumn{4}{|c|}{ Ref } \\
\hline & $\leq 10$ Years & $1.89(1.15-3.14)$ & 0.013 & $1.47(0.83-2.58)$ & 0.184 \\
\hline & $>10$ Years & $1.83(1.04-3.22)$ & 0.035 & $\mathrm{I} .67(0.77-3.6 \mathrm{I})$ & 0.195 \\
\hline \multirow{2}{*}{ Working status } & Working women & \multicolumn{4}{|c|}{ Ref } \\
\hline & Housewife & $1.28(0.72-2.26)$ & 0.400 & $0.96(0.46-1.99)$ & 0.918 \\
\hline Monthly & $\leq 10,000$ & \multicolumn{4}{|c|}{ Ref } \\
\hline Household & $11,000-20,000$ & $0.77(0.46-I .26)$ & 0.29 & $0.85(0.49-1.48)$ & 0.567 \\
\hline Income (PKR) & $>20,000$ & $0.95(0.54-1.65$ & 0.84 & $0.8 I(0.43-I .5 I)$ & 0.500 \\
\hline
\end{tabular}

Ref: Reference Category (category of comparison for the other categories); *: Significant P-value; Cl: Confidence Interval 
breast feeding. The unadjusted estimates showed that maternal age, education level, and residence were significantly associated with early initiation of breast feeding among mothers. The mothers in rural areas had 2.I (95\% Cl: 1.4-3.3, $\mathrm{p}=0.00 \mathrm{I})$ higher unadjusted odds of EIBF as compared to those living in urban areas of Charsadda. Similarly, mothers in the age group of $26-35$ years had 1.8 odds $(95 \% \mathrm{Cl}$ : I. I6-2.88, $\mathrm{p}=0.009$ ) while mother aged 25 years or less had 1.6 higher unadjusted odds for EIBF, though association was not significant $(95 \% \mathrm{Cl}$ : $0.82-3.36, p=0.156)$.

The results of multivariable logistic analysis showed that only maternal residence and age groups were significantly associated with EIBF, after adjusting for other covariates. The rural mothers had 2.1 (95\% Cl: 1.3 - 3.5, $\mathrm{p}=0.002$ ) higher adjusted odds of EIBF when compared to urban mothers of Charsadda. Similarly, mothers in the age group of $26-35$ years had $1.8(95 \% \mathrm{Cl}$ : I.I - 2.9, $p=0.025)$ higher adjusted odds of EIBF when compared to mothers of 35 years or more. The association of maternal education, working status, and household monthly income with early initiation of breastfeeding was insignificant.

\section{DISCUSSION}

The cross-sectional study, a part of KPIHS, was conducted in district Charsadda. Half of the women were between 26-35 years of age, fifty percent had no school education, almost two-third were rural resident, and about $42 \%$ had a monthly household income between 11,000 20,000 PKR. More than half $(59 \%)$ of the participants reported the early initiation of breast feeding. The practice of early initiation of breast feeding was found to be higher among adult mothers (26-35 years), and those living in rural areas.

Benefits of EIBF for mothers and newborn are well documented., Immediately after birth the sucking reflex is most vigorous and neonates are more alert during the first hour after birth and if neonates are put to mother's breast within this period, likelihood of exclusive breastfeeding increases. ${ }^{12}$ Despite of the recognized benefits of early initiation of breastfeeding, two out of five women did not initiated breast feeding within first hour of birth in our study. Similarly in a population based study in Sindh less than half of women (49\%) breastfed their within one hour of birth. ${ }^{8}$ Zafar et al. reported a rate of $26.3 \%$ in their study. ${ }^{10}$ Most importantly, a decrease has been observed in the practice of EIBF from 46 percent in 2006-07 to 19.6 percent in $2017-18 .^{5,6}$

The rate of EIBF in our study varied from those reported in PDHS 2017-18 and Pakistan National Nutrition Survey 2018 (NNS) ${ }^{13}$, both at National and provincial levels. According to PDHS $2017-18$, every fifth child (19.6\%) was breastfed within one hour of birth, varying from 12 percent in Punjab to 59 percent in Baluchistan with 18 percent in $\mathrm{KP}^{5}$. While the NNS 2018 reported the rate of 45.8 percent for Pakistan, varying from $20.1 \%$ in Gilgit Baltistan to $61.1 \%$ in Baluchistan and 46.9 percent in KP (NNS) $2018 .{ }^{13}$ The variations in data from different surveys may reflect the differences in methodologies related to sampling, study population and data collection. However, the large geographic variation in IYCF and EIBF rates may need further research.

In other South Asian countries, the EIBF rates vary from $27.5 \%$ in Bangladesh ${ }^{14}$, $38.6 \%$ in India 745 to $72.7 \%$ in Nepal, and $83.3 \%$ in Sri Lanka'. Similarly $\mathrm{El}-\mathrm{Gilany} \mathrm{H}$, et al. also found that one in ten women ( $11.4 \%$ ) initiated breastfeeding within first hour after birth in Saudi Arabia. ${ }^{15}$ Such discrepancy in the rates of EIBF within countries may reflect the geographical, ethnic, cultural and socioeconomic differences of populations from different countries.' Inappropriate feeding practices are suggested to be a greater determinant of inadequate intakes than the availability of foods in the households. ${ }^{12}$ Cultural practice of feeding pre-lacteals is suggested to contribute to delayed initiation of breast feeding and the low rate of exclusive breastfeeding ${ }^{10,16}$, and discarding the first milk (colostrum) ${ }^{17,18}$ are suggested to contribute to delayed initiation of breast feeding. However, the factors other than socio-economic and demographic characteristics were not explored in our study.

Maternal socio-demographic factors have been reported as important determinants of infant and child feeding practices. ${ }^{14}$ In our study almost twothird of participants were rural residents and three out of four respondents were housewives. Half of the women were between 26 to 35 years of age and uneducated. The sociodemographic factors associated with early initiation of breast feeding practices include maternal age and area of residence. However, maternal education, working status and monthly income were not identified as significant determinants of EIBF.

Maternal age is identified as important determinant of EIBF. Our study showed that mothers between 26 and 35 years were 1.8 times the odd more likely to initiate breast feeding within one hour after birth (as compare to mother above 35 years of age), while association of young maternal age ( $<25$ years) with EIBF could not be established. Similarly, studies in Philippines, ${ }^{19}$ and Australia ${ }^{20}$ favored older maternal age group, and found significant association of old maternal age with early initiation of breast feeding. Contrary to our study findings, research evidence also suggests that mothers under 25 years of age have higher odds of initiation of breastfeeding within one hour of birth. ${ }^{21}$ While other studies identified maternal age equal of thirty five or more as a negative factor for early initiation of breast feeding. As more mothers are entering the workforce and that age is a fixed characteristic, more efforts should be made to target the mothers who did not initiate EBF. The older age effect on EIBF remains to be elucidated. ${ }^{22}$ On the other handsome studies could not found significant difference in practicing early initiation of breastfeeding among mothers from different age groups. ${ }^{23,24}$

The residence by rural/urban area is another factor found to be associated with EIBF in our study. The practice of EIBF was two times more commonly practiced by mothers from rural areas. Contrary to findings in our study the practice of early initiation of 
breastfeeding was found to be three percentage points higher in urban areas than in rural areas, according to NNS $2018 .{ }^{13}$ While PDHS 2018 indicated that the practice of early initiation of breastfeeding did not differ by rural/urban area of residence (18\%) in Pakistan. ${ }^{5}$ Secondary data analysis of Bangladesh Demographic and Health Survey of 2004 showed that mothers from urban areas were more likely to delay the initiation of breastfeeding after birth. The data also suggested that the practice of initiating breastfeeding within the first hour was higher in mothers from richer households. ${ }^{14}$ Rapid urbanization and migration of the rural population to urban areas for work may have had an impact on breastfeeding practices. ${ }^{10}$

Maternal education, working status and monthly income were not found to be associated in our study though these were identified as significant determinants of EIBF in other studies. In a study by Sharma et al. maternal education, occupation, and economic status were found to be significantly associated with EIBF. ${ }^{7}$ Patel $A$, et al. ${ }^{25}$ revealed that higher maternal education was associated with timely initiation of breast feeding. The mother's formal education was also identified as a significant factor associated with EIBF in a study by Liben and Yesuf in Ethiopia. ${ }^{26}$ Argument is that educated mothers were less likely to delay initiation of breastfeeding and they feed their children with more attention, discipline, purpose, and this could explain the association observed. ${ }^{27}$ In our study the EIBF was mostly practiced by educated women, although the association was not significant after adjusting for confounding factors. Though not a significant factor in our study, maternal employment was found to be positively associated with the EIBF in a study by Khan, et al. ${ }^{8}$ On the contrary, Tabish, et $\mathrm{al}^{28}$ in his study found that working mothers were I.5 times less likely to initiate breast-feeding within one hour after birth.

Economic status of maternal household has been identified as an important factor associated with early initiation of breastfeeding in other studies. Khanal, et al. ${ }^{9}$ in their study found that mothers from the lowest wealth quintile were most likely to initiate breastfeeding in the first hour of childbirth. Author is of the opinion that mothers from poor socio-economic background might not have access or capacity to buy expensive breast milk substitutes, leaving the breastfeeding as the only choice. However, author suggested qualitative research to explore the reasons for delay initiation of breastfeeding among mothers from the highest wealth quintile. However, in a study by Mihrshahi, et al. ${ }^{14}$, the rate of initiating breastfeeding within the first hour was higher in mothers from richer households. The literature has mixed results on maternal household income on EIBF. Our study could not found association of household monthly income with EIBF.

To begin with the strengths, this study was part of Khyber Pakhtunkhwa Integrated Population Health Survey (KP-IPHS), 2016-17. KP-IPHS was a first population based cross-sectional survey conducted in 24 districts of KP, including district Charsadda. Multi staged stratified cluster random sampling was used to get a representative sample. The findings of the study can be generalized to the population of district Charsadda. Initial sample was 716; however, the final sample was 357 due to non-response of participants/missing data. Based on our study statistics i.e number of children been breast fed within first hour after birth $(n=357)$ and prevalence of EIBF (59.1\%), the power of $90.91 \%$ was achieved for study, using "openepi" software for sample size calculation. ${ }^{29}$ The study investigated socio-demographic factors associated with EIBF. However, other important determinants of EIBF including cultural practices, obstetric characteristics of mothers, factors related to child and family were not investigated in our study and need further research. As this was a cross-sectional survey, we cannot establish temporal and cause effect relationship of EIBF with its determinants. The recall bias may be there as information was collected by asking mothers about IYCF they were practicing since childbirth. Further research into other districts would be helpful in understanding the EIBF patterns on a broader scale. This evidence generated may be used by policy makers to develop effective policies and programs for improving infant feeding practices. Awareness could be raised among young mothers and women in urban areas through promotion programs, regardless of education and economic factors. In a long run, it may contribute towards better population health, poverty reduction, economic growth and sustainable development.

\section{CONCLUSION}

The study concluded that more than half of the children under two years at district Charsadda of KP, Pakistan were breastfed within first hour after birth. Residence, maternal age group, and school education had a strong association with EIBF. Given the nutritive and immunological benefits of EIBF, promotion of breast-feeding within first hour will contribute toward reducing neonatal mortality in Pakistan, which has remained unchanged for last two decades.

\section{ACKNOWLEDGEMENTS}

Authors are grateful to Dr. Talal Ahmed Raza, Surgical Division Medical Teaching Institution Lady Reading Hospital, Peshawar for providing help in manuscript drafting.

\section{REFERENCES}

I. World Health Organization (WHO). Infant and young child feeding. 2018. [Accessed on: January $0 \mathrm{I}$, 2019]. Available from URL: https://www.who.int/en/newsroom/fact-sheets/detail/infant-andyoung-child-feeding.

2. World Health Organization (WHO). Malnutrition: Fact sheet. 2019. [Accessed on: January 03, 2019]. A vailable from URL: https://www.who.int/newsroom/fact-sheets/detail/ malnutrition.

3. Global database on the implementation of Nutrition Action (GINA). Pakistan Infant and Young Child Feeding Strategy, 2016- 2020. 2015. [Accessed on: January 03 , 
2019]. Available from URL: https://extranet.who.int/nutrition/g ina/sites/default/files/PAKInfant\%20and\%20Young\%20Child \%20Feeding\%20Strategy_\%2020 15\%20Final.pdf

4. World Health Organization (WHO). Infant and young child feeding: Model Chapter for textbooks for medical students and allied health professionals.2009. [Accessed on: January 03, 2019]. Available from URL: https://www.who.int/ maternal_child_adolescent/docum ents/978924I597494/en/.

5. National Institute of Population Studies (NIPS) and ICF. Pakistan Demographic and Health Survey 2017-18. 2019. [Accessed on: January 03, 2019]. Available from URL: https://dhsprogram.com /pubs/pdf/FR354/FR354.pdf.

6. Imran $\mathrm{M}$, Jabeen $\mathrm{N}$, Khatoon $\mathrm{S}$. Feeding practices of infants and young children according to whom Indicators at Children Hospital, Islamabad. Pak J Med Health Sci 2017; II(I):215-19.

7. Sharma A, Thakur PS, Tiwari R, Kasar PK, Sharma R, Kabirpanthi V. Factors associated with early initiation of breastfeeding among mothers of tribal area of Madhya Pradesh, India: a community based cross sectional study. Int J Community Med Public Health 2017;3(I):194-9. DOI: 10.18203 /2394-6040.ijcmph20I5I56I.

8. Khan GN, Ariff S, Khan U, Habib A, Umer M, Suhag $Z$, et al. Determinants of infant and young child feeding practices by mothers in two rural districts of Sindh, Pakistan: A cross-sectional survey. Int Breastfeed J 2017;12:40. DOI: |0.||86/s|3006-0|7-0|3|-z.

9. Khanal V, Scott JA, Lee AH, Karkee $R$, Binns CW. Factors associated with Early Initiation of Breastfeeding in Western Nepal. Int J Environ Res Public Health 20I5; I2(8):9562-74. DOI: I0.3390/ijerph I 20809562.

10. Zafar M, Fatmi Z, Shafi K. Determinants of child feeding practices in Pakistan; secondary data analysis of demographic and health survey 2006-07. J Med Nutr Nutraceuticals 20I4;3(2):78-84. DOI: 10.4103/2278-019X.131958.

I I. UI-Haq Z, Fazid S, Sultana N, Hisam A, Shah BH, Arif N, et al. Khyber Pakhtunkhwa Integrated Population Health Survey (KP-IPHS) 2016-I7. Khyber Med Univ J 20 I 9; I I (4):2547.DOI:I0.35845/kmuj. 2019. 19423.

12. World Health Organization (WHO) .Complementary feeding. 2019. [Accessed on: January 03, 2019]. Available from URL: http:// www.who.int/nutrition/topics/com plementary_feeding/en/.

13. Nutrition Wing, Ministry of Health Services, Regulation and Coordination. National Nutrition Survey 2018: Key findings Report. 2018. [Accessed on: January 03, 2019]. Available from URL: https://www.unicef.org/pakistan/sit es/unicef.org.pakistan/files/201907/Final\%20Key\%20Findings\%20 Report\%202019\%20\%281\%29.p df.

14. Mihrshahi S, Kabir I, Roy SK, Agho KE, Senarath U, Dibley MJ. Determinants of infant and young child feeding practices in Bangladesh: secondary data analysis of Demographic and Health Survey 2004 . Food Nutr Bull 20 I 0;3 I (2):295-3 I 3. DOI: I0. I I77/ |5648265|003|00220.

I5. El-Gilany AH, Sarraf B, AI-Wehady A. Factors associated with timely initiation of breastfeeding in AlHassa province, Saudi Arabia. East Mediter H e a l t h J 20I2; I8(3):250-4. DOI: 10.267|9/ 2012. 18.3 .250

16. National Institute of Population Studies (NIPS) and ICF International. Pakistan Demographic and Health Survey 2012-13.2013. [Accessed on: January 03, 2019]. Available from URL:https://dhsprogram.com /pubs/pdf/FR290/FR290.pdf

17. Hailemariam TW, Adeba E, Sufa A. Predictors of early breastfeeding initiation among mothers of children under 24 months of age in rural part of West Ethiopia. BMC Public
Health 20I5;I5(20I5):I076. DOI: |0.| |86/s | 2889-0| 5-2420-z.

18. Atyeo NN, Frank TD, Vail EF, Sperduto WAL, Boyd DL. Early Initiation of Breastfeeding Among Maya Mothers in the Western Highlands of Guatemala: Practices and Beliefs. J Hum Lact 20I 7;33(4):78I-9. DOI: I0.II77 /08903344I6682729.

19. Senarath U, Dibley MJ, Agho KE. Factors associated with nonexclusive breastfeeding in 5 east and southeast Asian countries: a multilevel analysis. J Hum Lact 2010;26(3):248-57. DOI: 10.1 I77/ 0890334409357562.

20. Fisher J, Hammarberg K, Wynter K, McBain J, Gibson F, Boivin J, et al. Assisted conception, maternal age and breastfeeding: an Australian cohort study. Acta Paediatr 2013;102(10):970-6. DOI: I0.1 III /apa. 12336.

21. Ekubay M., Berhe A., Yisma E. Initiation of breastfeeding within one hour of birth among mothers with infants younger than or equal to 6 months of age attending public health institutions in Addis Ababa, Ethiopia. Intl Breastfeed J 20 I 8; I 3:4 DOI: 10.1 |86/sI3006-0I8-0I46-0. eCollection 2018.

22. Kitano N, Nomura K, Kido M, Murakami K, Ohkubo T, Ueno M, et al. Combined effects of maternal age and parity on successful initiation of exclusive breastfeeding. Prev Med Rep 2015;3:121-6. DOI: 10.1016/j.pmedr.2015.12.010

23. Karim F, Billah S.M, Chowdhury MAK, Zaka N, Manu A, Arifeen SE, et al. Initiation of breastfeeding within one hour of birth and its determinants among normal vaginal deliveries at primary and secondary health facilities in Bangladesh: A case-observation study. PLoS ONE 20।8; I3(8): e0202508. DOI: I0.137|/journal.pone.0202508.

24. Ahmed AE., Salih OA. Determinants of the early initiation of breastfeeding in the Kingdom of Saudi Arabia. Int Breastfeed J 20I9;|4:I3. DOI: I0.II86/s|3006- 


\section{9-0207-z.}

25. Patel A, Banerjee A, Kaletwad A. Factors associated with prelacteal feeding and timely initiation of breastfeeding in hospital-delivered infants in India. J Hum Lact 2013;29(4):572-8. DOI: 10.1177 /08903344I 24747 I 8.

26. Liben ML, Yesuf EM. Determinants of early initiation of breastfeeding in Amibara district, Northeastern Ethiopia: a community based crosssectional study. Int Breastfeed J
20|6; II:7. DOI: I0.II86/s|3006016-0067-8.

27. Mukunya $D$, Tumwine JK, Nankabirwa V, Ndeezi G, Odongo I, Tumuhamye J, et al. Factors associated with delayed initiation of breastfeeding: a survey in Northern Uganda. Global Health Action 2017 ; I0(I). DOI: I0.1080/ 16549716.2017.1410975.

28. Hazir T, Akram D-S, Nisar YB, Kazmi N, Agho KE, Abbasi S et al. Determinants of suboptimal breast- feeding practices in Pakistan. Public Health Nutr 2012;16(4):659-72. DOI: $10.1017 /$ SI3689800I 20029 35.

29. Dean AG, Sullivan KM, Soe MM. OpenEpi: Open Source Epidemiologic Statistics for Public Health,Version, www. Open Epi.com,updated 2013/04/06. [Accessed on: January 03, 2019] Available from URL: https://www. openepi.com/Menu/OE_Menu.ht.

\section{AUTHORS' CONTRIBUTIONS}

Following authors have made substantial contributions to the manuscript as under:

Al: Conception, analysis and interpretation of data, drafting the manuscript, final approval of the version to be published.

ZUH: Conception, study design, data collection, critical review, final approval of the version to be published

NS \& SF: Analysis and interpretation of data, drafting the manuscript, critical review, final approval of the version to be published.

Authors agree to be accountable for all aspects of the work in ensuring that questions related to the accuracy or integrity of any part of the work are appropriately investigated and resolved.

CONFLICT OF INTEREST
Authors declared no conflict of interest
GRANT SUPPORT AND FINANCIAL DISCLOSURE
Financial support by United Nations Population Fund (UNFPA)

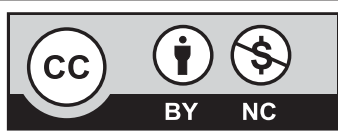

This is an Open Access article distributed under the terms of the Creative Commons Attribution-NonCommercial 2.0 Generic License

KMUJ web address: www.kmuj.kmu.edu.pk

Email address: kmuj@kmu.edu.pk 